\title{
Leptospirosis in pigs, dogs, rodents, humans, and water in an area of the Colombian tropics
}

\author{
Alfonso Calderón • Virginia Rodríguez • Salim Máttar • \\ Germán Arrieta
}

Accepted: 5 November 2013 /Published online: 21 November 2013

(C) Springer Science+Business Media Dordrecht 2013

\begin{abstract}
Leptospirosis is a reemerging zoonosis of global distribution and is one of the causes of hemorrhagic fevers in the tropics. We sought to determine seroprevalence in humans and animals and isolate Leptospira interrogans sensu lato in domestic animals, rodents, and water sources. The study was conducted in a tropical area of the middle Sinú in Cordoba, Colombia. In a prospective descriptive study, we collected blood and urine from pigs and dogs, sera from rural human workers, sera and kidney macerates of rodents, and water samples from environmental sources. We used microagglutination to screen for antibodies to 13 serovars. Strains were cultured on the Ellinghausen-McCullough-Johnson-Harris medium and confirmed by PCR amplifying lipL32 gene. Seroprevalence was $55.9 \%$ in pigs, $35.2 \%$ in dogs, and $75.8 \%$ in humans; no antibody was detected, and no Leptospira were isolated from kidney macerates of rodents. Seven $L$. interrogans sensu lato strains were isolated: three from pigs, two from dogs, and two from water. High seroprevalence in pigs, dogs, and humans, concomitant to isolation of strains, demonstrates that in Cordoba, transmission exists among animals, the environment, and humans, which warrants the implementation of public health intervention measures to reduce the epidemiological impact of leptospirosis in the region.
\end{abstract}

Keywords Epidemiological surveillance · Transmission · Zoonoses $\cdot$ Public health $\cdot$ Disease reservoirs $\cdot$ Social environment

\footnotetext{
A. Calderón $(\bowtie) \cdot V$. Rodríguez $\cdot S$. Máttar $\cdot$ G. Arrieta Department of Animal Sciences, Institute of Investigations Biologics of Tropic, University of Cordoba (Colombia), Cordoba, Colombia e-mail: alcaran1@yahoo.com

G. Arrieta

Public Health and Healthcare, Corporación Universitaria del Caribe, Sincelejo, Colombia
}

\section{Introduction}

Leptospirosis is a zoonosis of global distribution; it is considered a reemerging disease, endemic in tropical countries, which, because of their geoclimatic and social conditions, favor its transmission (Guerra 2013). In domestic and wild animals, chronic renal carriers maintain viable leptospires which may be excreted via urine becoming a source of infection for humans and other animals (Monahan et al. 2009). Humans can be infected with any serovar of Leptospira from any animal or environment, basically, through contact with fluids from infected animals (Lim 2009; Marga et al. 2013).

The organisms may enter the body via lacerations in the skin, contact with mucosa or conjunctiva, inhalation of aerosols, or ingestion of contaminated food or beverages (Monahan et al. 2009; Musso and La Scola 2013). Leptospirosis is considered an occupational disease, primarily affecting farmers, fishermen, veterinarians, and workers in sewers and slaughterhouses (Brown et al. 2011). A risk of infection for humans is the exposure during water-related recreational activities (Monahan et al. 2009; Marga et al. 2013).

The tropical environment favors survival of Leptospira outside reservoirs in stagnant or slowly flowing warm water. Water and soil contaminated by excreta of infected animals are also infection sources (Ganoza et al. 2006; Adler and Peña 2010). In recent years, this ecological aspect has gained importance, because of the increased incidence of exposure to contaminated environments (Vijayachary et al. 2008). Our aim was to measure the seroprevalence of Leptospira infection in humans and animals and isolate Leptospira interrogans sensu lato from animals and water sources.

\section{Materials and methods}

Type of study and geographic location We conducted a prospective, descriptive study between 2009 and 2011. The farms 
studied were dedicated to pig farming and located in Monteria $\left(8^{\circ} 46^{\prime} 15^{\prime \prime} \mathrm{N}, 75^{\circ} 51^{\prime} 31^{\prime \prime} \mathrm{O}\right)$, Cerete $\left(8^{\circ} 52^{\prime} 22^{\prime \prime} \mathrm{N}, 75^{\circ} 46^{\prime} 47^{\prime \prime} \mathrm{O}\right)$, and Cienaga de Oro $\left(8^{\circ} 52^{\prime} 44^{\prime \prime} \mathrm{N}, 75^{\circ} 42^{\prime} 8^{\prime \prime} \mathrm{O}\right)$. The three municipalities (Fig. 1) are located according to the departmental territorial geographic plan in a middle region of the Sinú River in the department of Cordoba, Colombia.

Study of pigs, dogs, rodents, and humans The total population of pigs in reproductive age in the three municipalities studied was 19.328. Considering a seroprevalence maximum (50\%), $95 \%$ reliability, and $5 \%$ standard error, the sample size for the microagglutination test (MAT) was 377 , but blood samples were taken from 383 pigs in 18 farms. Bacterial cultures were performed according to the MAT results, and we took at each farm ten urine samples, such as four pigs with titres from $1: 100$ to $1: 400$, four with titres $\geq 1: 400$, and two with negative serologic results. This study included 54 dogs living on the study farms, and 39 rodents were captured with Sherman traps randomly distributed in different areas of the farms such as domestic areas, stables, and package store; the distribution of rodent species was Mus musculus, $49 \%(n=19)$; Rattus norvegicus, $31 \%(n=12)$; and Rattus rattus, $21 \%(n=8)$.
There were no rodents captured in five farms. The study included 62 workers who inhabited and worked on the farms and volunteered to participate.

Study of water We analyzed 54 water sources that were proportionally distributed among the farms selected. These sources included animal drinking water $(n=18)$, water from wells $(n=18)$, and wastewater from pig stables $(n=18)$.

Serology There were 383 sera of pigs, 54 of dogs, 39 of rodents, and 62 of humans analyzed by MAT. We screened for antibodies against $L$. interrogans sensu lato using the MAT according to specifications of the International Office of Epizootics; 11 serovars were used: serogroup Australis (serovar Bratislava), serogroup Autumnalis (serovar Autumnalis), serogroup Batavie (serovar Batavie), serogroup Serjoe (serovar Hardjo), serogroup Grippotyphosa (serovar Grippotyphosa), serogroup Icterohaemorrhagiae, (serovar Icterohaemorrhagiae), serogroup Mini (serovar Mini), serogroup Pomona (serovar Pomona), serogroup Pyrogenes (serovar Zanoni), serogroup Tarassovi (serovar Tarassovi),
Fig. 1 Geographical distribution of $L$. interrogans sensu lato in Cordoba, Colombia

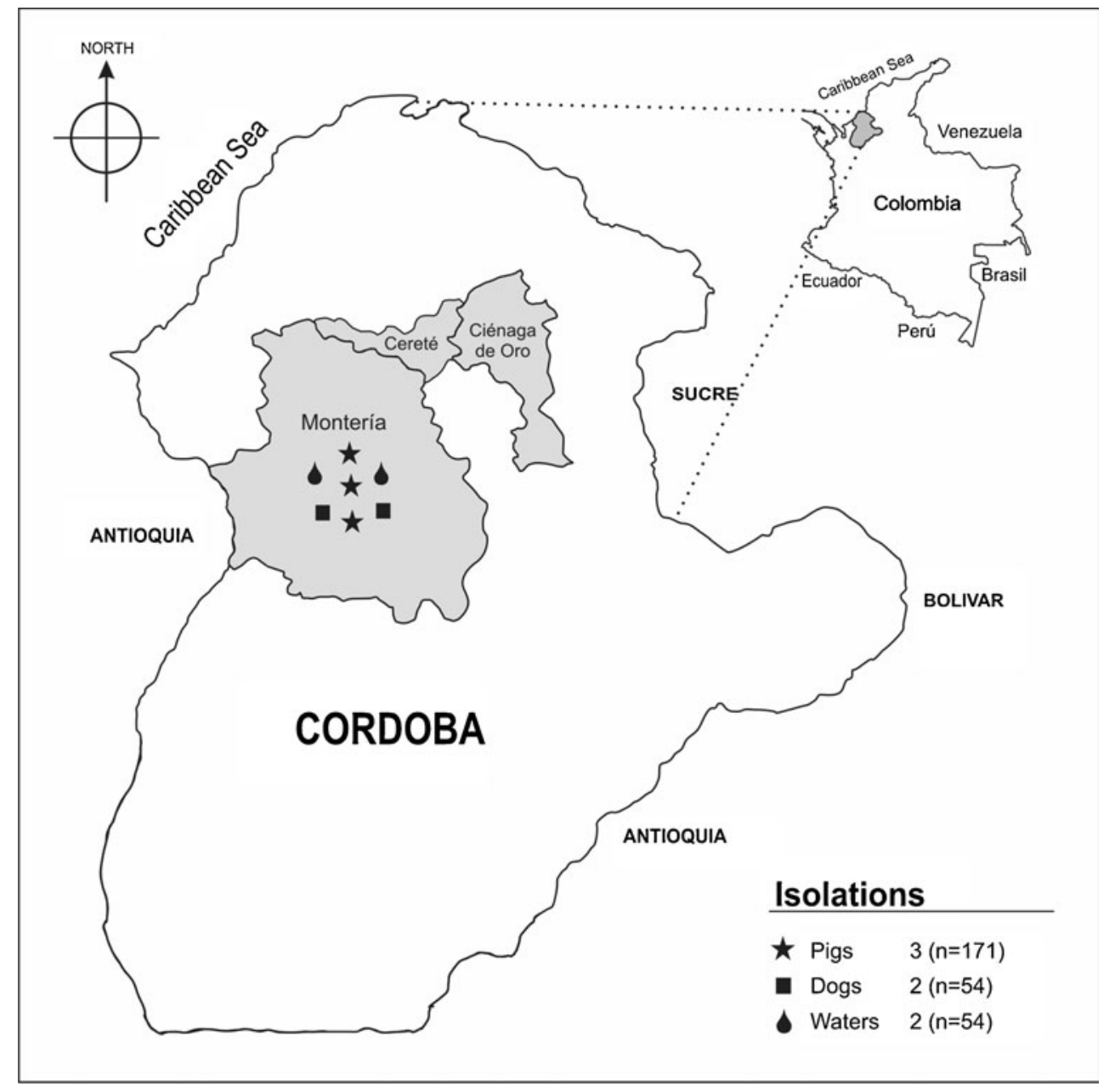


and serogroup Canicola (serovar Canicola). Titres $\geq 1: 100$ were considered positive.

L. interrogans culture in urine and water Following MAT, 183 pig samples were selected for bacteriological cultures, but 12 urine samples were lost, and only 171 were cultured: 20 with negative serology, 75 with titres between 1:100 and $1: 400$, and 76 with titres $>1: 400$. The urine samples of the 54 dogs and 54 water samples were also cultured. Samples were cultured in Ellinghausen-McCullough-Johnson-Harris $(\mathrm{EMJH})$ medium (Difco, Detroit, MI, USA), enriched with $1 \%$ rabbit serum with and without supplementing nalidixic acid and 5-fluorouracil. Approximately $0.5 \mathrm{ml}$ of the water and urine samples was seeded directly onto the EMJH medium; $2 \mathrm{ml}$ was filtered through a $0.45-\mu \mathrm{m}$ nitrocellulose membrane, and $0.5 \mathrm{ml}$ was inoculated onto the EMJH medium. The cultures were incubated at $29-30^{\circ} \mathrm{C}$ and examined weekly under dark-field microscopy for 4 months.

L. interrogans from cultures of kidney macerates of rodents Upon necropsies, one kidney was collected from each rodent, sectioned in half, and macerated in $2 \mathrm{ml} \mathrm{PBS}$ at $\mathrm{pH}$ $7.2 ; 0.5 \mathrm{ml}$ of the suspension was inoculated directly in the EMJH medium. The rest was deposited in $5 \mathrm{ml}$ of PBS at $\mathrm{pH}$ 7.2 and allowed to stand at $30{ }^{\circ} \mathrm{C}$ for $30 \mathrm{~min}$. After this incubation, $0.5 \mathrm{ml}$ of the supernatant medium was inoculated in EMJH medium.

Molecular identification The DNA was extracted from field isolates, meaning Leptospira isolates (strains) obtained in the field study and maintained in the laboratory. Cultures were used between 6 and 10 days of growth; $5 \mathrm{ml}$ was taken and centrifuged at 13,000 rpm. The pellet was resuspended in $1 \mathrm{ml}$ of TE. The DNA extraction was done with the Qiagen kit (QIAamp ${ }^{\circledR}$ DNA Mini Kit). Confirmation of pathogenic strains was conducted by using $270 \mathrm{~F}$ and $692 \mathrm{R}$-specific primers that amplify a 423-bp fragment, which encodes for the Lip 32 protein (Levett et al. 2005). The conditions of the PCR reaction mixture were as follows: $1 \times$ PCR buffer, $1.25 \mathrm{nM}$ dNTPs, $2.5 \mathrm{mM} \mathrm{MgCl} 2,1 \mathrm{mM} \mathrm{270F}$ initiator, $1 \mathrm{mM} 692 \mathrm{R}$ initiator, and Taq DNA pol $0.4 \mathrm{U}$. Each PCR cycle was $94{ }^{\circ} \mathrm{C} \times 1 \mathrm{~min}, 55^{\circ} \mathrm{C} \times 1 \mathrm{~min}$, and $72{ }^{\circ} \mathrm{C} \times 2 \mathrm{~min}$; 34 cycles were performed.

Ethical aspects The Ethics Committee at the Institute of Investigations Biologics of Tropic (IIBT) at the University of Cordoba reviewed and approved the study protocol, considering articles 5 and 87 from decree 309 of 25 February 2000 from the Colombian Ministry of the Environment (2000). For the human population, farm workers were invited to participate on a volunteer basis through signed consent; the work was classified as minimum risk according to the Colombian Ministry of Health (008430/1993).

\section{Results}

Serological results The seroprevalence found were as follows: pigs, $55.9 \%$ (214/383); dogs, $35.2 \%$ (19/54); humans, $75.8 \%$ (47/62); and rodents, $0 \%(0 / 39)$. The percentage distribution by serogroups in the species studied is shown in Table 1.

Pig urine culture Of 171 pig urine samples cultured, three Leptospira strains were isolated in females in Montería and two of them were obtained in the same farm. Two females showed titres $\geq 1: 800$ for serovars Pomona, Tarassovi, Canicola, Grippotyphosa, and Icterohaemorrhagiae, while in the third female, the higher reactivity was 1.400 for serovar Pomona.

Dog urine culture Two isolates were obtained. One was from a seronegative dog; the other dog had titres of 1:100 for Serjoe and Batavie serogroups (1:200 for Grippotyphosa, Canicola, Tarassovi, and Mini serogroups; and 1:400 for Australis, Icterohaemorrhagiae, Pyrogenes, and Autumnalis serogroups).

Rodent culture From 39 cultures of kidney macerates, no Leptospira strains were isolated.

Water culture From 54 water samples, nine strains were isolated, but only two were identified as L. interrogans sensu lato in Monteria. The first strain was obtained from animal drinking water and the second from wastewater.

Rodents No Leptospira were isolated from the kidney of rodents.

Molecular identification The PCR identified seven isolates (three in pigs, two in dogs, and two water samples) like pathogenic strains, which amplified a product of about $423 \mathrm{bp}$ of the gene lipL32 of pathogenic Leptospira.

Table 1 Percentage distribution of serogroups of L. interrogans sensu lato among different species in the middle Sinú area

\begin{tabular}{llll}
\hline Species/serogroup & Pigs \% & Dogs \% & Humans \% \\
\hline Mini & 28.7 & 7.4 & 32.2 \\
Batavie & 34.7 & 9.2 & 37.1 \\
Serjoe & 40.2 & 9.2 & 43.5 \\
Tarassovi & 40.4 & 14.8 & 35.4 \\
Autumnalis & 42.8 & 11.1 & 50.0 \\
Australis & 43.6 & 14.8 & 38.7 \\
Grippotyphosa & 47.7 & 18.5 & 53.2 \\
Pyrogenes & 50.3 & 11.1 & 38.7 \\
Icterohaemorrhagiae & 56.4 & 14.1 & 54.8 \\
Pomona & 61.6 & 18.5 & 56.4 \\
Canicola & 62.4 & 14.1 & 64.5 \\
\hline
\end{tabular}




\section{Discussion}

Isolates of Leptospira from the urine of pigs and dogs and from water sources demonstrate high endemicity and a potential public health problem in this area of the Colombian Caribbean. The infection was confirmed with high seroprevalence in pigs and dogs, which helps to explain the very high prevalence of antibody in the human population at risk.

In contrast with our results from the Caribbean, lower seroprevalences have been reported in the Colombian Andes (Table 2). The higher seroprevalence in pigs in the Caribbean region may be due to geoclimatic conditions such as high precipitation and relative humidity, sanitary deficiencies, and a higher number of nontechnical pig farms in the Caribbean.

Our negative findings for Leptospira infection in domestic rodents could indicate the existence of an unknown wild or domestic reservoir that is important for the maintenance of infection in the pig population in our study area. The highest seroprevalence in pigs in our study was for serogroups Canicola, Pomona, and Icterohaemorrhagiae (Table 1), suggesting transfer of specific serovars between pigs and dogs.

Given the lack of vaccination records against leptospirosis in dogs, the $35.2 \%$, seroprevalence in dogs probably represents past infections. In our study, the Pomona and Grippotyphosa serogroups presented the highest frequency, followed by Canicola, Icterohaemorrhagiae, Australis, and
Sejroe (Table 1). The Pomona serogroup has been classified as emergent in dog's leptospirosis, and these titres may be due to contact with other dogs and with reservoir skunks or raccoons for these serogroups (Ribotta et al. 2000), which are common animals in these tropical areas of Colombia. In Brazil, only $7.1 \%$ seroprevalence was found in dogs, and it was concluded that the presence of Leptospira in the environment was the source of infection (Table 2).

The very high seroprevalence in humans may be due to the population evaluated (occupational risk), to the endemicity of leptospirosis in humid tropical regions where environmental conditions favor transmission of Leptospira, and to permanent contact with pigs and dogs. The highest seroreactivity of the exposed human population was to serogroups Canicola, Pomona, and Icterohaemorrhagiae (Table 1). Close contact of these individuals with dogs was noted in the farms. Ours is the first study on a human population in Colombia that reports on antibodies against the Mini, Tarassovi, and Batavie serogroups (Table 1). Antibody to these serovars was also found in dogs and pigs from these same farms. Forty percent (25/62) of the seropositive humans had no compatible symptomatology, and $35 \%$ (22/62) manifested compatible symptoms during the previous 9 months. The most frequent symptoms were cephalalgia, myalgia, fever, and malaise. The lack of symptomatology compatible with a clinical picture of leptospirosis (jaundice, kidney failure, liver failure) confirms the
Table 2 Seroprevalence of Leptospira interrogans sensu lato in different countries

\begin{tabular}{|c|c|c|c|c|}
\hline Country & Area of influence & Seroprevalence (\%) & Serovars & References \\
\hline \multicolumn{5}{|l|}{ Pigs } \\
\hline Colombia & Caribbean & 55.9 & 13 & Present study \\
\hline \multicolumn{5}{|l|}{ Dogs } \\
\hline Brazil & Paraná & 7.1 & 24 & Oliveira et al. 2012 \\
\hline Brazil & Paraná & 12.2 & 30 & Fonzar and Langoni 2012 \\
\hline USA & Michigan & 24.9 & 6 & Stokes et al. 2007 \\
\hline USA & Washington & 17.1 & 6 & Davis et al. 2008 \\
\hline Thailand & Bangkok & 83.5 & ND & Jittapalapong et al. 2009 \\
\hline Mozambique & Mayotte & 93.1 & 8 & Desvars et al. 2012 \\
\hline & & 87.5 & & \\
\hline Colombia & Tolima & 20.2 & 5 & Romero et al. 2010 \\
\hline Colombia & Tolima & 21.4 & 5 & Romero et al. 2010 \\
\hline Colombia & Caribbean & 35.2 & 13 & Present study \\
\hline \multicolumn{5}{|l|}{ Humans } \\
\hline Brazil & Paraná & 8.0 & 30 & Fonzar and Langoni 2012 \\
\hline Peru & Lima & 1.2 & 22 & Platts et al. 2011 \\
\hline USA & & 2.5 & 6 & Whitney et al. 2009 \\
\hline Portugal & Azores Islands & 22.0 & 26 & Vieira et al. 2006 \\
\hline Mexico & Veracruz & 4.0 & 13 & Navarrete et al. 2006. \\
\hline Italy & Bari & 0.0 & 19 & Monno et al. 2009 \\
\hline New Zealand & & 9.5 & 2 & Benschop et al. 2009 \\
\hline Colombia & Tolima & 6.0 & 5 & Romero et al. 2010 \\
\hline Colombia & Caribbean & 75.8 & 13 & Present study \\
\hline
\end{tabular}


high endemicity in the study area associated with asymptomatic infections or anicteric forms characterized by general nonspecific signs and symptoms; however, those patients also did not remember clinical manifestations, suggesting that leptospirosis reveals the possibility of the disease being asymptomatic or underreported, or associated with other hemorrhagic diseases such as dengue, malaria, hepatitis A and E, fever, and other hemorrhagic fevers (Musso and La Scola 2013; Chaudhry et al. 2013).

The serological and bacteriological negative results in rodents may be due to serial rodent control on the farms. Domestic cats were also observed; cats could have prevented a permanent population of rodents on the farms. In contrast to our results, Bunnell et al. (2000) found $20 \%$ seroprevalence in wild rodents in the Peruvian Amazon. Agudelo et al. (2010) found $25.2 \%$ seroprevalence in $R$. norvegicus in a food market in Medellin, Colombia, and concluded that serovar Icterohaemorrhagiae has been established in rodents, and these act as carriers of pathogenic leptospires for susceptible humans.

Presence of two pathogenic Leptospira was demonstrated in water sources, which constitutes a risk to human and animal public health. Studies on the role of water in transmitting leptospirosis such as those of Lesem et al. (2010) in Israel reported that most human cases were acquired from activities related to water sources. Viau and Boehm (2011) in Hawaii evidenced the presence of pathogenic Leptospira genomes in coastal waters during the Hawaiian rainy season. Chusri et al. (2012) demonstrated pathogenic leptospires in water rafting practices. Lagi et al. (2013) in Italy reported on the transmission of leptospirosis from water sources. Garvey et al. (2013) in Ireland concluded that the increased incidence of leptospirosis is associated with contact with animals or water sports, and Agampodi et al. (2013) in Sri Lanka reported on an outbreak of leptospirosis in clerks participating in a water sport event.

The need for rapid diagnosis of leptospirosis has led to the development of numerous PCR assays, which offers great advantages compared with isolation. This method is rapid, sensitive, specific, and robust. There have been developments on PCR assays for detection of universal genes as Gryb, rrs, and $\sec Y$, or genes restricted to pathogenic leptospires as lipL32, $l f b 1$, ligA, and ligB2 (Musso and La Scola 2013). The use of PCR for detecting the lipL32 gene fragment was useful to distinguish between pathogenic isolates and saprophytes.

Conventional PCR assays are being replaced by real-time PCR (qPCR) for the detection of pathogenic leptospires in urine, kidney, fetuses, and reproductive downloads. Detection and quantification of DNA from pathogenic Leptospira was performed using specific primers for the gene Lip32. In southwestern Iran, it has been allowed to detect pathogenic leptospires in the kidney, urine, and blood of cattle samples (Azizi et al. 2012) and in Dublin in urine canine samples (Rojas et al. 2010), highlighting the increased risk of zoonotic diseases in these regions.
Furthermore, from the environmental view, it allows investigating whether or not the water sources (rivers, ponds, troughs) are contaminated with pathogenic leptospires. In France, qPCR was performed using the detection and quantification of Lip 32 gene in water samples. The method represents a tool that could be integrated into future programs of public health surveillance in recreational waters (Vein et al. 2012). The detection and monitoring of pathogenic leptospires in water allow intervention measures to help reduce the occurrence of leptospirosis in humans and animals.

\section{Conclusion}

The high seroprevalence that we found in pigs, dogs, and humans and the isolation of seven strains of $L$. interrogans sensu lato in pigs, dogs, and water demonstrate that transmission exists among animals, the environment, and humans, which originates from endemic zones demarcated for this zoonoses in Cordoba. The high prevalence of $L$. interrogans sensu lato in Cordoba warrants the implementation of public health intervention measures to reduce the epidemiological impact of leptospirosis in the region.

\section{References}

Adler, B., Peña M.A., 2010. Leptospira and leptospirosis, Veterinary Microbiology, 140, 287-296.

Agampodi, S.B., Karunarathna, D., Jayathilala, N., Rathnayaka, H., Agampodi, T.C. and Karunanayaka, L., 2013. Outbreak of leptospirosis after white-water rafting: sign of a shift from rural to recreational leptospirosis in Sri Lanka?, Epidemiology and Infection, 26, 1-4.

Agudelo, F.P., Arango, J.C., Merizalde, E., Londoño, F.A., Quiroz, V.H., Rodas, J.D., 2010. Evidencia serológica de circulación de Leptospira spp en Rattus norvegicus naturalmente expuestos en una zona urbana colombiana, Revista de Salud Pública, 12, 990-999.

Azizi, S., Tajbakhsh, E., Hajimirzaei, M.R., Varnamkhast, M., Sadeghian, H. and Oryan, A., 2012. Evaluation of 'white-spotted kidneys' associated with leptospirosis by polymerase chain reaction based LipL32 gene in slaughtered cows, Journal of the South African Veterinary Association, 83, 69-74.

Brown, P.D., McKenzie, M., Pinnock, M. and McGrowder, D., 2011. Environmental risk factors associated with leptospirosis among butchers and their associates in Jamaica, The International Journal of Occupational and Environmental Medicine, 2, 47-57.

Bunnell, J.E., Hice, C.L., Watts, D.M., Montruelil, V., Tesh, R.B. and Vinetz, J.M., 2000. Detection of pathogenic Leptospira spp. infections among mammals captured in the Peruvian amazon basin region, The American Journal of Tropical Medicine and Hygiene 63, 255-258.

Chaudhry, R., Das, A., Premlatha, M.M., Choudhary, A., Chourasia, B.K., Chandel, D.S. and Dey, A.B.., 2013. Serological and molecular approaches for diagnosis of leptospirosis in a tertiary care hospital in north India: a 10-year study. Indian Journal Medical Researches, 137, 785-90.

Chusri, S., Sritrairatchai, S., Hortiwahul, T., Charoenmak, B., Silpapojakul, K., 2012. Leptospirosis among river water rafters in Satoon, southern Thailand, Journal of the Medical Association of Thailand, 95, 874-877. 
Davis, M.A., Evermann, J.F., Petersen, C.R., Vancer, S.J., Besser, T.E., Huckabee, J., Daniels, J.B., Hancock, D.D., Leslie, M. and Baer, R., 2008. Serological survey for antibodies to Leptospira in dogs and raccoons in Washington State, Zoonoses and Public Health, 55, 436-442.

Desvars, A., Naze, F., Vourc'h, G., Cardinale, E., Picardeau, M., Michault, A. and Bourhy, P., 2012. Similarities in Leptospira serogroups and species distribution in animals and humans in the Indian Ocean island of Mayotte, The American Journal of Tropical Medicine and Hygiene, 87, 134-140.

Fonzar, U.J., Langoni, H., 2012. Geographic analysis on the occurrence of human and canine leptospirosis in the city of Maringá, state of Paraná, Brazil, Revista da Sociedade Brasileira de Medicina Tropical, 45, 100-105.

Ganoza, C.A., Matthias, M.A., Collins, R.D., Brouwer, K.C., Cunningham, C.B., Eddy, R., Segura, E.R., Gilman, R.G., Gotuzzo, E. and Vinetz, J.M., 2006. Determining risk for severe leptospirosis by molecular analysis of environmental surface waters for pathogenic Leptospira. PLoS Med, 3, 1329-1340.

Garvey, P., Connell, J., O'Flanagan, D. and McKeown, P., 2013. Leptospirosis in Ireland: annual incidence and exposures associated with infection, Epidemiology and Infection, 5,1-9.

Guerra, MA., 2013. Leptospirosis: Public health perspectives, Biological Products, 4, 295-297.

Jittapalapong, S., Sittisan, P., Sakpuaram, T., Kabeya, H., Maruyama, S. and Inpankaew, T. 2009. Coinfection of Leptospira spp and Toxoplasma gondii among stray dogs in Bangkok, Thailand, The Southeast Asian Journal of Tropical Medicine and Public Health, 40, 247-252.

Levett, P., Morey, R.E., Galloway, R.L., Turner, D.E., Steigerwalt, A.G. and Mayer, L.W., 2005. Detection of pathogenic leptospires by realtime quantitative PCR, Journal of Medical Microbiology, 54, 45-49.

Lagi, F., Corti, T., Meli, M., Pinto, A. and Bartoloni, A., 2013. Leptospirosis acquired by tourists in Venice Italy, Journal of Travel Medicine, 20, 128-130.

Lesem, E., Segal, T., Barnea, A., Yitzhaki S., Ostfeld, I., Pitlik, S. and Schwatz, E., 2010. Travel related leptospirosis in Israel: A nationwide study, The American Journal of Tropical Medicine and Hygiene, 82, 459-463.

Lim, V., 2009. Occupational infections, The Malaysian Journal of Pathology, 31(1), 1-9.

Marga, G.A.G., Kimberly, R. B., Tamara A.T.E.D., Suzanne J. K. and Rudy A. H., 2013. Human Leptospirosis Trends, the Netherlands 1925-2008, Emerging Infectious Diseases, 19(3), 371-378.

Ministry of Health. Resolution 008430/1993. By which standards are established scientific, technical and administrative health research. Available from: http://www.dib.unal.edu.co/promocion/etica_res_ 8430_1993.pdf

Ministry of the Environment. Decree 309/2000 (February 25). By regulating scientific research on biodiversity. Available from: http://www. minambiente.gov.co/documentos/dec_0309_250200.pdf

Monahan, A.M., Miller, I.S. and Nally, J.E., 2009. Leptospirosis: Risks during recreational activities, Journal of Applied Microbiology, 107, $707-716$.
Monno, R., Fumarola, L., Trerotoli, P., Cavone, D., Giannelli, G., Rizzo, C., Ciceroni, L. and Musti, M., 2009. Seroprevalence of Q fever, brucellosis and leptospirosis in farmers and agricultural workers in Bari Southern Italy, Annals of agricultural and environmental medicine, 16, 205-209.

Musso, D. and La Scola, B., 2013. Laboratory diagnosis of leptospirosis: A challenge, Journal of Microbiology, Immunology and Infection, $46,245-252$

Navarrete, E.J., Acevedo, V.A., Huerta, H.E., Torres, B.J., Gavaldón, R.D., 2006. Prevalencia de anticuerpos contra dengue y leptospira en la población de Jáltipan, Veracruz, Salud pública de México, 48(3), 220-228.

Oliveira, L.M., Said, R.A., Strenzel, G.M. and Langoni, H., 2012. Seroprevalence of anti-Leptospira spp. antibodies in dogs in Bahia, Brazil, Preventive Veterinary Medicine 1, 79-84.

Platts, M.J.A., La Rochelle, P., Campos, K., Vinetz, J.M., Gotuzzo, E. and Ricaldi, N.J., 2011. Seroprevalencia de Leptospirosis en Puente Piedra, Lima en el año 2006, Revista peruana de medicina experimental y Salud Pública, 28, 273-276.

Rojas, P., Monahan, A.M., Schuller, S., Miller, I.S., Markey, B.K. and Nally, J.E., 2010. Detection and quantification of leptospires in urine of dogs: a maintenance host for the zoonotic disease leptospirosis, European Journal of Clinical Microbiology \& Infectious Diseases, $29,1305-1309$.

Ribotta, M., Higgins, R., Gottschalk, M. and Lallier, R., 2000. Development of an indirect enzyme-linked immunoabsorbent assay for the detection of leptospiral antibodies in dogs, Canadian Journal of Veterinary Research, 64, 32-37.

Romero, P.M., Sánchez, V.J. and Hayek, L., 2010. Prevalencia de anticuerpos contra Leptospira en población urbana humana y canina del Departamento del Tolima, Revista de Salud Pública, 12, 268275.

Stokes, J.E., Kaneene, J.B., Schall, W.D., Kruger, J.M., Miller, R., Kaiser, L. and Bolin, C.A., 2007. Prevalence of serum antibodies against six Leptospira serovars in healthy dogs, Journal of the American Veterinary Medical Association, 230, 1657-1664.

Vein, J., Perrin, A., Berny J P., Benoit, E., Leblond A. and Kodj, A., 2012. Adaptation of a real-time PCR method for the detection and quantification of pathogenic leptospires in environmental water, Canadian Journal of Microbiology, 58, 828-835.

Viau, E.J., Boehm, A.B.., 2011. Quantitative PCR-based detection of pathogenic Leptospira in Hawaiian coastal streams, Journal of Water and Health, 9, 637-646.

Vieira, M.L., Gama, S.M.J. and Collares, P.M., 2006. Human leptospirosis in Portugal: a retrospective study of eighteen years. International Journal of Infectious Diseases, 10, 378-386.

Vijayachary, P., Sugunan, A.P. and Shriram, A.N., 2008. Leptospirosis: an emerging global public health problem, Journal of Biosciences, 33, 557-569.

Whitney, E.A., Ailes, E., Myers, L.M., Sliki, J.T. and Berkelman, R.L., 2009. Prevalence of and risk factors for serum antibodies against Leptospira serovars in US veterinarians, Journal of the American Veterinary Medical Association, 234, 938-944. 